\title{
In this issue of food security - June 2021
}

\section{Serge Savary ${ }^{1}$}

Published online: 14 June 2021

(C) International Society for Plant Pathology and Springer Nature B.V. 2021

\section{Announcement}

Goedele Van den Broeck accepts to be senior editor for economy at food security

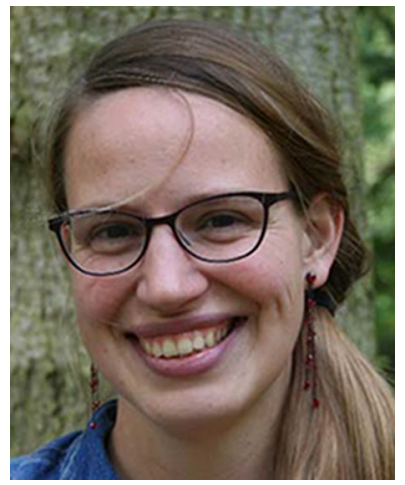

Dr. Van den Broeck is an assistant professor in agricultural economics at the Earth and Life Institute at UC Louvain in Belgium. Her research focuses on food value chains, rural labor, agricultural trade and food policy, with specific attention to gender and nutrition issues. She has extensive experience with survey design and data collection, and has field work experience in Mexico, Senegal, Uganda and Vietnam. She holds a MSc degree in Bio-Science Engineering and $\mathrm{PhD}$ degree in agricultural economics from KU Leuven. Her doctoral dissertation was awarded with the Carl K. Eicher award for Best $\mathrm{PhD}$ on Africa from the Internal Association of Agricultural Economists. Prior to joining UC Louvain, she was a visiting researcher at Wageningen University, University of Göttingen and the World Bank.

Dr. Van den Broeck will especially cover the aspects of policies, global exchanges, and their implications across the scales of food security, including households and individuals, and a range of dimensions, nutrition and gender included.

Serge Savary

serge.savary@inrae.fr

1 INRAE, l'Institut national de recherche pour l'agriculture, l'alimentation et l'environnement, Auzeville, France
This June 2021 issue of food security includes 15 very different articles coming from very different places in the world

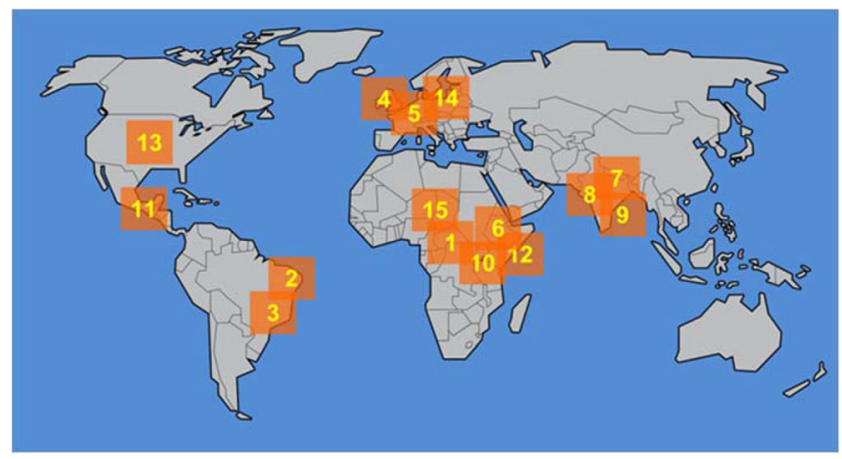

- Article 1 deals with the "Revolution of Greens" in subSahelian Africa. This review, led by Pepijn Schreinemachers (one of the Associate Editors of this journal) documents how important and why major and necessary changes in vegetable seed took place in Africa, following a path which profoundly differ from the one of the famed Green Revolution, which occurred for field crops.

- Articles $\mathbf{2}$ and $\mathbf{3}$ and $\mathbf{4}$ deal with food security in cities, from different viewpoints: the first from Brazil (Poliana de Araújo Palmeira et al.) looks at a municipality in the Brazilian Nordeste, the other from Maria Alvim Leite et al. considers districts in Juiz de Fora, Minas Gerais, Brazil, and the third, urban food system of the city of Leeds in the United Kingdom (Jensen and Orfila).

- The two next articles have an urban setting. Article 5, by Sibbing and Candel address the possible gap between the citizens' call in Ede, The Netherlands for the development of integrated food policies and the implementation of genuine institutionalization of food system challenges across local administrations. Article 6, by Lilia Bliznashka et al., addresses the suboptimal diets of cattle in Addis Ababa, Ethiopia, and considers the dietary diversification efforts in animal source food. 
- The scale at which food insecurity occurs is vital. It is essential to understand how insecurity appears, develops, and persists. But it also is obviously crucial for policies to be properly targeted. Strangely, there are no very clear ways to achieve precise mapping of food insecurity. In a landmark article, Guha and Chandra, in Article 7, explain exactly what to do in the State of Uttar Pradesh in India. A similar theme is addressed by Sudipta Paul in a different part of India (Article 8).

- Agricultural technology, especially new seed, must reach farmers. In Article 9, Anjani Kumar et al. quantify the relative importance of various geographical and administrative factors that may affect the diffusion process of modern crop varieties in India. With a different approach, Gideon Danso-Abbeam et al. address (Article 10) a similar question in the case of sweet potato in Rwanda.

- Home gardens are life-lines, repositories for diversity, sources for income, and family resources. Article 11 (Jennifer Castañeda-Navarrete) documents home-garden diversity and food security in southern Mexico. In a similar line of thoughts, Ndoli et al. (Article 12) explain why on-farm trees are a safety net for the poorest households rather than a major contributor to food security in Rwanda.
- Food is cultural. Inadequate access to cultural foods can create cultural stress and affect one's identity and wellbeing. The question is addressed by Kathrine E Wright (Article 13) in second-generation U.S. American (SGA) students.

- Food insecurity impacts the elderly in the Global North. The case of Poland is analyses by Gajda and JeżewskaZychowicz in Article 14.

- The last article (Article 15) of this June Issue of Food Security, by van de Ven et al. is titled: " Living income benchmarking of rural households in low-income countries", and addresses the intense discussion around the 'living income' of smallholder farmers involved in the production of commodities for international supply chains.

- The last item of this issue is a Book Review performed by the Deputy-Editor-in-Chief of Food Security, Stephen Waddington, on Keijiro Otsuka and Shenggen Fan's "Agricultural Development: New Perspectives in a Changing World". 